\title{
DESIGN AND EXPERIMENTAL INVESTIGATION OF AN ADDITIVE MANUFACTURED COMPACT DRIVE
}

\author{
Gunnar Matthiesen $^{1 *}$; Daniel Merget ${ }^{2}$; Tobias Pietrzyk ${ }^{1}$; Stephan Ziegler²; Johannes \\ Henrich Schleifenbaum ${ }^{2,3}$; Katharina Schmitz ${ }^{1}$ \\ ${ }^{1}$ Institute for Fluid Power Drives and Systems, RWTH Aachen University, Germany \\ ${ }^{2}$ Digital Additive Production, RWTH Aachen University, Germany \\ ${ }^{3}$ Fraunhofer Institute for Laser Technology ILT, Germany \\ * Corresponding author: Tel.: +49 241 8047730, E-mail address: gunnar.matthiesen@ifas.rwth-aachen.de
}

\begin{abstract}
In recent years, additive manufacturing (AM) has become one of the most revolutionary and promising technologies in manufacturing. The process of making a product layer by layer is also often referred to as $3 \mathrm{D}$ printing. Once employed purely for prototyping, AM is now increasingly used for small series production, for example in aerospace applications. The paper starts with a motivation for AM in hydraulic applications and the development of an AM internal gear pump. For a better understanding of the manufacturing process, a brief introduction to AM highlighting the advantages and challenges is given. The AM internal gear pump is part of an electrohydraulic power pack, which is used to power an electrohydraulic actuator (EHA). The power pack contains all necessary peripherals to realise the hydraulic system of the EHA. The AM process allows for new design possibilities, but the process differs strongly compared to subtractive manufacturing processes and therefore is outlined here. The paper concludes by presenting measurement results of the AM internal gear pump.
\end{abstract}

Keywords: Additive Manufacturing, LPBF, Internal gear pump, Electrohydraulic power pack, Design for Additive Manufacturing

\section{MOTIVATION}

Hydraulic components are still mostly produced using traditional manufacturing processes, for example with milling machines, lathes, electric discharge machining, laser cutting or casting. These are mainly CNC-supported manufacturing processes which, with well-coordinated process control, enable high economies of scale in series production. On the downside, there are high ramp-up times for setting up the machines in production lines for series production of new parts. This makes it difficult to implement small batches quickly and economically. In addition, the design freedom of a component is severely restricted by these traditional manufacturing processes, since each process has its own requirements for accessibility to the component, such as lathing which is only possible orthogonally or coaxially to the lathing axis.

Since fluid technology has paid little attention to AM and the research in this field is still focused on increasing efficiency, this paper aims to highlight the opportunities for fluid power arising through AM.

Currently, AM's market penetration is still hindered by lack of design knowledge, high production costs and limited productivity. But as the AM industry is currently growing exponentially, it is essential for each technical domain to evaluate the potential benefits from $\mathrm{AM}$ and leverage those.

This paper shows the potential of AM in hydraulic applications. For this purpose, the drive train of the ifas gimmick is used to demonstrate possibilities of AM by redesigning the drivetrain and integration pump and valves into a single light weight housing. The ifas gimmick is a hydraulic driven labyrinth presented at the 11. ifk in Aachen (see Figure 1). Two electrohydraulic direct drives are used in the ifas gimmick to realise the rotation around the $\mathrm{x}$-axis and $\mathrm{y}$-axis. Direct drive here means that there are no valves used for controlling the movement of the hydraulic cylinder. The movement is controlled by the rotational speed of the hydraulic pumps. 
Each hydraulic pump is driven by a $24 \mathrm{~V}$ DC electrical motor, typically used for the electrohydraulic steering in trucks.

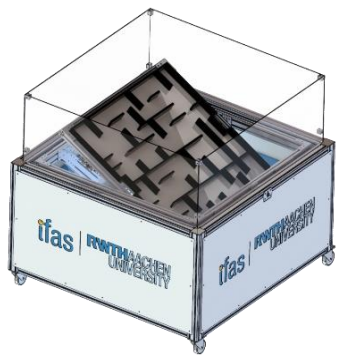

Figure 1: The ifas gimmick presented at the $11^{\text {th }}$ ifk

\section{ADDITIVE MANUFACTURING}

\subsection{AM Introduction}

So far, adoption of AM has been highest in industries where the higher production costs of AM processes are outweighed by the additional value AM can generate through improved product functionality, higher production efficiency, bigger customization and shorter time to market.

According to ASTM, an AM process is a "process of joining materials to make parts from 3D model data, usually layer upon layer" [1], as opposed to subtractive (e.g. milling) or formative (e.g. bending) manufacturing [2]. Many different manufacturing processes are listed under the label AM, often sharing similarities as well as advantages and disadvantages due to the common layered manufacturing principle. The most important advantage is the high possible part complexity. Most AM processes make it possible to produce undercuts, internal and highly complex structures as well as fluid channels with freeform cross section geometry and placement. This can lead to an improved part functionality or a better function-to-weight-ratio.

One important disadvantage is that AM materials often exhibit anisotropies, with material properties such as tensile strength, elongation at break or heat transfer coefficient in the $\mathrm{z}$ direction (build direction) being different from

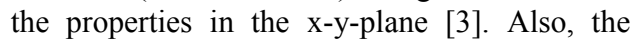
layered manufacturing usually leads to a stairstepping effect on slanted surfaces, resulting in a higher surface roughness compared to machined samples.
Another critical disadvantage affecting the manufacturing of slanted surfaces (also called overhangs) is shared by many AM processes: The build process is only stable when the angle between the overhang and the substrate exceeds a critical value (Figure 2). For angles smaller than the critical angle, the build process becomes unstable and huge part deformations occur, often leading to a process failure. The reason is that material can't be placed "in thin air". These areas need support structures to be manufacturable, which can take significant amounts of time and work to be removed after the build process.

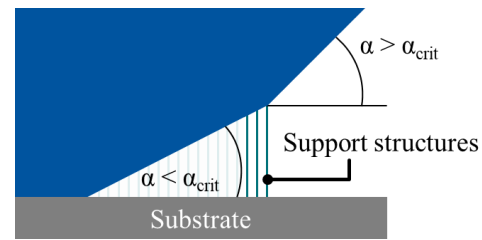

Figure 2: Critical overhang angle

\subsection{LPBF}

Laser Powder Bed Fusion (LPBF) is the most common additive manufacturing process for the production of dense metal parts [4]. A part is manufactured by selectively melting consecutive thin layers (approx. $30 \mu \mathrm{m}$ ) of metal powder by a laser beam according to a digital slice model of the part. The process principle is shown in Figure 3. A detailed description of the process can be found in [5].

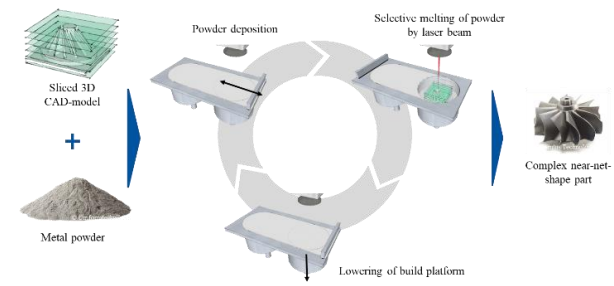

Figure 3: The LPBF process steps [3]

A wide range of materials can be processed by LPBF. Standard materials commercially available from many suppliers include, among others, Aluminum alloys (AlSi10Mg, AlSi12), stainless and tool steels $(1.4404,1.4542,1.2709)$, Nickel-based alloys (Inconel 718 and 625) as well as pure Titanium (Titanium Grade 2) and Ti6AlV4 $[7,8]$. The typical powder used in the process consists of spherical particles with a particle diameter in the range of $15 \mu \mathrm{m}-45 \mu \mathrm{m}$. 
The powder is fully melted in the process, resulting in a relative density usually exceeding $99.5 \%$. The rapid solidification rate of up to $7 \cdot 10^{6} \mathrm{~K} / \mathrm{s}$ of the molten material generally leads to a fine and homogeneous microstructure and high strength of the material [6], albeit often with anisotropies in the material properties. Heat treatments are available for the reduction of anisotropies or internal stresses. The material efficiency of the process is high, as the unmelted powder can be fully reused.

The cooldown and shrinkage of the bonded consecutive layers leads to a build-up of residual stresses in the material, as shown in Figure 4. When overhangs are produced, the residual stresses result in deformation and, when the overhang angle is below the critical angle, in failed builds. Support structures are therefore needed to counteract the stresses. The support structures and the typically rough surfaces of LPBF parts covered with partly melted powder particles $\left(R_{a}=10-20 \mu \mathrm{m}\right)$ generally require post-processing of the parts, consisting at least of (manual) removal of the support structures, abrasive blasting and, in case of functional surfaces with high quality requirements, machining. The need for support structures and thus for post-processing can be greatly reduced by a part design taking into account the process restrictions. [9, 19]

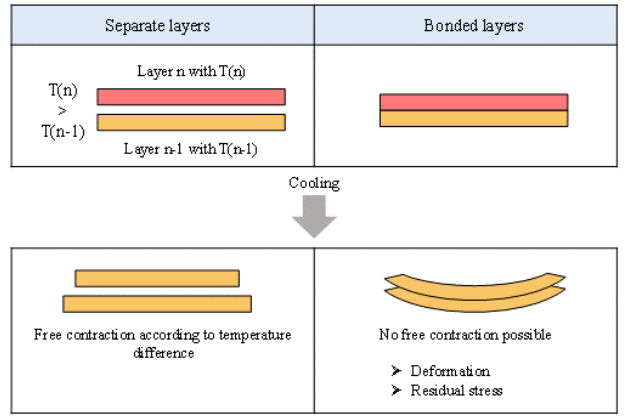

Figure 4: Build-up of residual stresses

For hydraulic applications, it is crucial that no powder particles or remains of support structures remain in part areas that later contain the hydraulic fluid, as this could damage critical parts of the hydraulic system. For this reason, it must be ensured that fluid channels and cavities are either designed in a way that doesn't require support structures, or that the support structures are mechanically removable, e.g. by designing without undercuts.

The geometric changes to achieve a design without the need for support structures can be comparably small, as shown for the cross-section of a fluid channel in Figure 5:

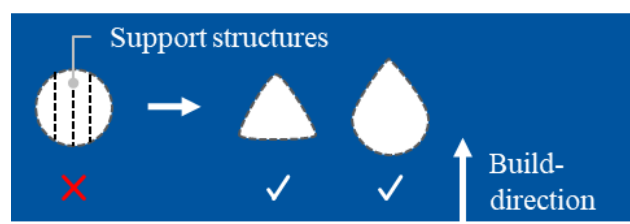

Figure 5: $\quad$ Altered cross-section of a fluid channel

\subsection{Additive Manufacturing and Hydraulic Systems}

AM has so far been limited to small components and is still primarily considered for prototyping. The possibilities for flow optimization are obvious, but at the same time also stresses introduced into the material at the points of flow deflection [10] can be reduced significantly. Within the same part volume, a higher volume flow with lower energy loss can be achieved with less material input due to reduced flow deflections [11]. Semini et al. also investigated the influence of the surface roughness for components that were treated by shot peening prior to the flow-through test to remove production residues from the surface. No significant effects of the surface on the flow were reported even after longer treatment time [12]. Weight savings of $30 \%$ and more can be achieved for fluid power components especially designed for AM. For complex hydraulic drive components, Guerrier et al. consider the achievement of a shorter development cycle, reduced storage costs for material, better and new repair possibilities promising [13]. A substitution of existing components by a new design for the exploitation of the advantages of additive manufacturing so far hardly has taken place. However, this process is especially interesting for fluid power technology because it offers great potential for flow-optimised design and an enormous lightweight construction potential through functional integration that conventional processes cannot enable. The potential compared to existing components results from the fact, that today's hydraulic components are manufactured mostly with subtractive processes, at the cost of limiting the design freedom of a component. 
Especially accessibility is an issue here. For example, valve blocks are hydraulic components with shapes largely determined by the production process. Except by means of primary shaping processes, which are frequently used in standardized valve blocks for mobile machines, it is not possible to manufacture internal connecting lines, so each channel must be led out of the component at least at one point. All channels must be placed in such a way that no unwanted connections occur and sufficient compressive strength is guaranteed. The aforementioned goals are contrary to the goals of lightweight construction, which is why a compromise in design must always be made. The special lightweight construction potential by means of $\mathrm{AM}$ arises in particular when the idea of function integration is consistently implemented and individual components or assemblies are fused to form a single component, for example when several housings are combined to accommodate components such as cartridge valves or pump gear sets in a single housing. The exploitation of this potential serves as motivation for the development of the powerpack presented below, which integrates the internal gear pump and valve blocks for the peripherals in one component. The additive manufacturing in combination with modern CAE tools speeds up and simplifies the production of a first prototype with sophisticated geometry.

\section{INTERNAL GEAR PUMPS}

The most common gear pumps in hydraulic applications are external and internal gear pumps. Both types of pumps are displacement pumps. An internal gear pump is used in this work due to the advantage of lower noise emission $[14,15]$. The components and the displacement process of an internal gear pump are shown in Figure 6. The external gear, the internal gear and the crescent are the main components of an internal gear pump. The external gear is typically used to drive the pump. In an internal gear pump, the fluid is displaced by decreasing the volume of the displacement chamber, similar to axial piston pumps. For gear pumps, the displacement chamber is formed by the tooth space volume (the volume between the teeth). The volume is decreased (and thus the fluid is displaced) by the meshing of the teeth, which leads to a reduction of the tooth space. At the low pressure port, the teeth move away from each other. The tooth space volume increases and is filled by the fluid. The low pressure side is separated from the high pressure side by the crescent and by the meshing teeth. Due to a small gap between the crescent and the tooth tips, leakage occurs and the pressure increases in this area. The pressure build-up can also be specifically influenced by pressure buildup grooves. If a gearing with a transverse contact ratio $>1$ is used, there are areas of tooth meshing where two tooth contacts are present. Due to the two tooth contacts, a small amount of fluid is trapped in between the contacts. The volume of the trapped fluid changes during the rotation. If the volume decreases, the fluid will be compressed and the pressure will increase. As a result, higher load forces as well as vibrations occur and can lead to higher noise emissions [16].

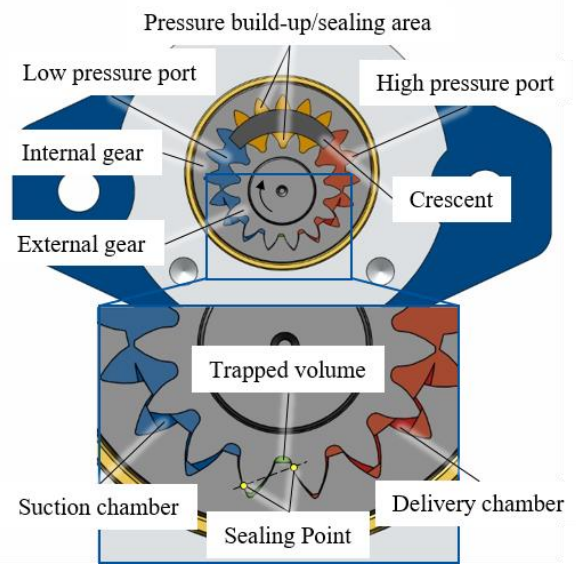

Figure 6: Components and displacement process of an internal gear pump

There are different designs of internal gear pumps. The most common designs available on the market are shown in Figure 7. At the top, an internal gear pump with axial inlet and outlet is shown. The fluid is sucked axially into the increasing tooth space volume and is displaced axially at the high pressure port. At the bottom of Figure 7, a pump design with radial inlet and outlet is shown. The fluid is displaced and flows through radial bores into the internal gear. This type of pump is often used in combination with gap compensation. The pump design with axial inlet and outlet also allows for a gap compensation. One example for the radial design with gap compensation is the prototype of a high 
speed internal gear pump developed at ifas [17]. For the AM power pack presented in this paper

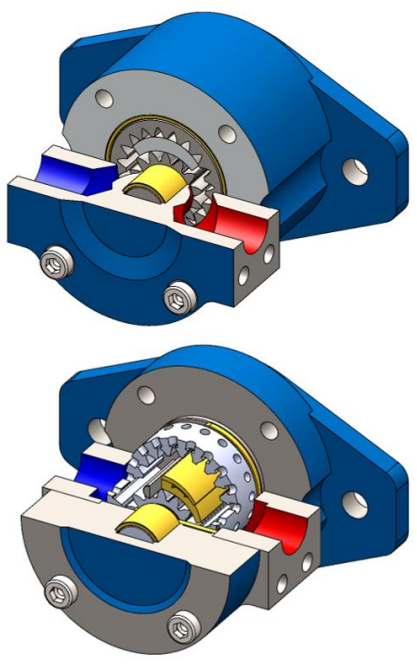

Figure 7: Different designs of internal gear pumps. Top: Axial inlet and outlet pump design. Bottom: Radial inlet and outlet pump design with gap compensation

an internal gear pump design with axial inlet and outlet without gap compensation is chosen. This allows for a compact pump design with very low noise emission as well as low flow pulsation [15]. Due to the application as an electro hydraulic direct drive in a hydraulic driven labyrinth at ifas, the low flow pulsation is a big advantage for the control strategy. The labyrinth serves as a highlight exhibit at the ifas booth during exhibitions and conferences. Therefore, a low noise emission is required. The pump design without gap compensation reduces the complexity of the pump as well as the total number of necessary components. Without the gap compensation, the manufacturing process and the tolerances become more important. The pump is able to work in four quadrant operation.

\section{DESIGN PROCESS}

For the design of the power pack, the redesign process proposed in [18] (see Figure 8) was carried out, which serves as a guideline for the redesign of conventionally manufactured components for additive manufacturing processes. According to the circuit diagram in Figure 9, an internal gear pump, two check valves and two pressure relief valves had to be integrated. In the beginning, external design restrictions were identified. The main restriction

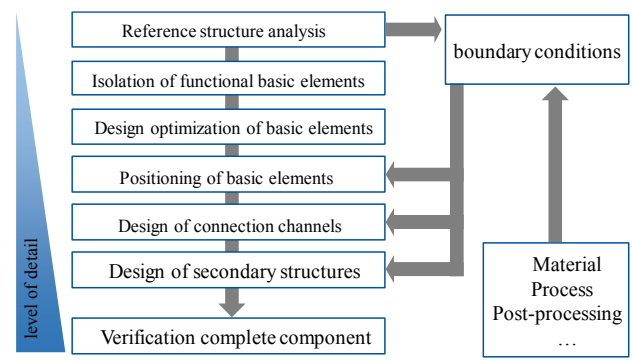

Figure 8: Design process for the redesign of additive hydraulic components [18]

found was the flange geometry, as the generous installation space in the gimmick allows for a great freedom in positioning the hydraulic ports and valves. Due to the coaxiality of shaft and gear set, further requirements for the installation space were derived from this, which had to be adhered to. Since the gear set was taken from a series pump, the ports in the gear chamber were designed identically in order to have comparability later with a variance only in the production process. The gear set originates from a pump with hydrodynamic bearing and thus features a leakage oil port. Since the EHA is operated in a closed circuit and preloaded (see Figure 9), a supply port had to be provided for preloading by an external filling pump. In order to minimize the number of hydraulic ports, the pressure relief valves were connected to the leakage port. Thus, at this point all connections between the components were fixed and only the arrangement and positioning of the valves remained. In order to determine the position of the valves, various configurations were determined and evaluated iteratively with regard to the required installation space, line length, flow control and the support structures required 
in the production process. In particular, the latter is a major problem as curved channels

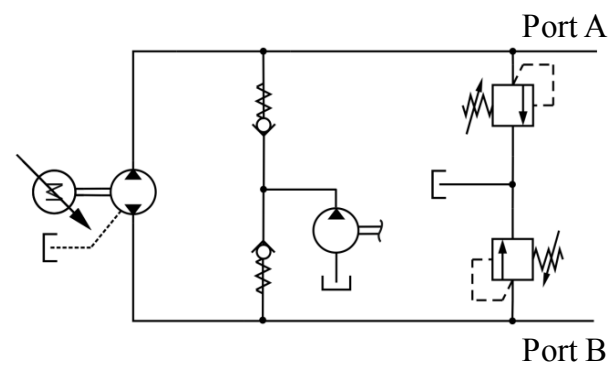

Figure 9: Hydraulic circuit diagram of the compact drive

are difficult to reach with tools such as chisels to remove the support structures without causing unwanted damage to the rest of the structure.

The selected final configuration is shown in Figure 10. In this configuration, all connections are easily accessible except the connections of the pressure relief valves (PRVs) and the tank port. These lines were designed small and with a geometrical shape to be printable without a support structure.

The final arrangement of the components is as follows: The port for the leakage (light blue) is provided at the top with a diameter of $5 \mathrm{~mm}$ and both PRVs are connected to that port via lines. The lines (not visible here) connecting the supply (purple) and main flow lines (dark blue) via check valves were chosen with a diameter of $6 \mathrm{~mm}$ as a compromise between good manufacturability and sufficiently large pipe diameters. The main flow line (dark blue) has a diameter of $10 \mathrm{~mm}$ adopted from the series pump from which the gear set was taken. The connection port for the supply (purple) can be seen at the front and a diameter $15 \mathrm{~mm}$ was chosen here. The bearing seat (red) is also indicated aswell as the gears (yellow).

\subsection{Design Optimization using CAE-Tools}

The next step was to design the structure of the housing. Whereas the geometry of a component manufactured subtractively is usually determined by the raw material used and is only reduced to a barely fatigue-resistant geometry in lightweight construction, the situation is different for AM. Here it makes little sense to strive for a geometry similar to well-known, conventionally manufactured components, as this leads to

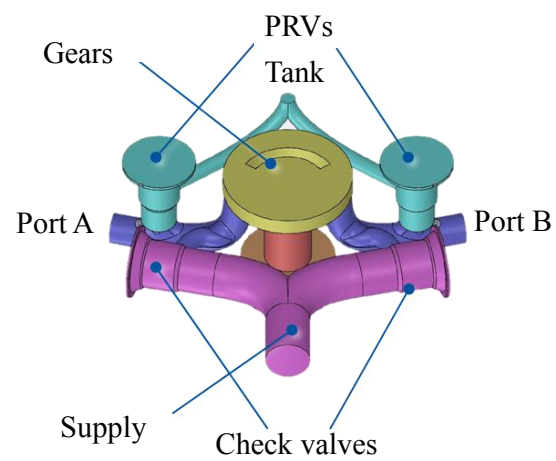

Figure 10: Positioning of all components

unnecessary structures that result in more material, production time, costs and weight. For complex structures, an iterative procedure of designing in a CAD program and subsequent verification using FEM is also conceivable in principle. If, however, one strives to minimize the part volume, this procedure is too inefficient. In order to solve this problem efficiently, various topology optimization algorithms are available. In this work, the software package ABAQUS was used. The 'Condition-based optimization'algorithm was used to obtain a rough solution quickly and to verify the boundary conditions. Due to the significantly higher computing time, the 'Sensitivity-based optimization'-algorithm was used to obtain the final solution only in a second step.

The optimization works as follows: A basic geometry (Figure 11, top) is transferred to the program. This geometry is segmented into individual volumes, each defining areas that may or may not be removed during the optimization. An FEM simulation is then set up including all boundary conditions and forces relevant for the component.

Also, objectives and constraints are set up for the optimization algorithm. In an iterative process, the part is then simulated and subsequently 
altered by the optimization algorithm. These two

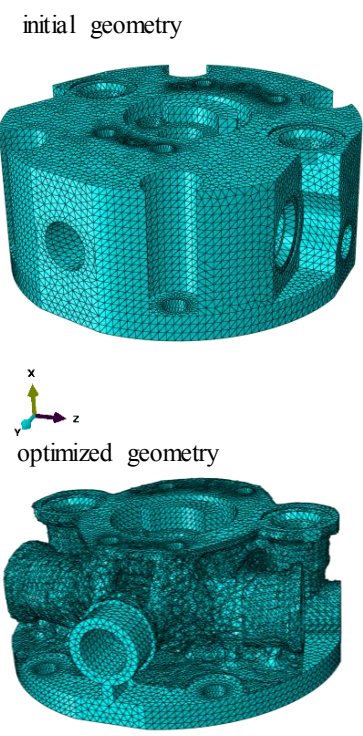

Figure 11: Initial and optimized geometry

steps are repeated until the optimization goals and constrains are reached. The optimization goal is usually given as a volume reduction. The whole optimization process was carried out iteratively in several variants in which different target volumes were defined. After an evaluation of the performance of each solution, the best solution was selected. In this case, the volume was reduced to $48.5 \%$ of the initial volume. The selected geometry is shown in Figure 11 (bottom). The resulting part exported from the program consists only of a triangulated mesh, which has to be translated back into a geometry that can be processed in the AM process chain. As the optimized geometry was created by deleting elements from the initial volume mesh, the surface of the exported part can have very uneven geometry that does not make sense as a technical surface. Therefore, the surface is smoothed in a post-processing step with different automatic and manual methods. The resulting part after smoothing is shown in Figure 12. As it is not yet possible to maintain high tolerances during additive manufacturing, additional material must be applied in the areas where high accuracy is required for a subsequent machining step. An additional material layer of $2 \mathrm{~mm}$ was applied to all relevant areas. The holes for the positioning pins and screws were completely closed, as these have to be machined anyway and the risk of deflecting the drills is thus avoided.

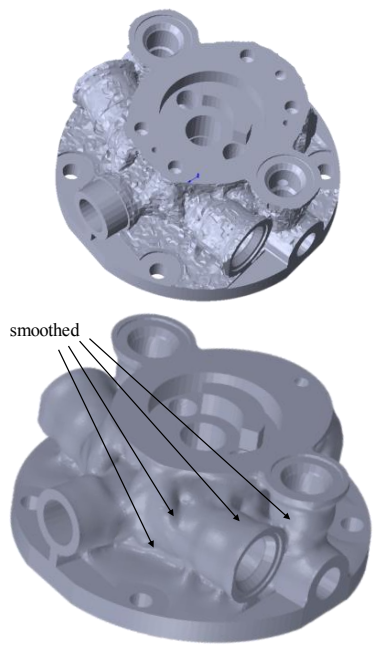

Figure 12: Pump housing before (top) and after (bottom) smoothing

\section{PRODUCTION PROCESSING}

AND

POST-

The pump housing and the housing cap were manufactured from 316L on an EOS M290 LPBF machine. The material was chosen because it has a similar thermal expansion coefficient compared to the material of the housing from which the gear set was taken. In this way, jamming between gear teeth and housing due to non-uniform thermal expansion should be avoided. The parts were then removed from the substrate plate by wire erosion. In principle, wire erosion is a process suitable for the production of highly flat surfaces. Unfortunately, the build-up of residual stresses during the LPBF process led to a deformation of the substrate plate. As this led to difficulties in referencing the part in the wire erosion process, the housing had to be re-aligned for further machining. Originally the flange was chosen as the reference and clamping surface for the following processing steps of the power pack. Due to the difficulties with wire erosion, a new reference surface had to be chosen. For the purpose of re-alignment, the shaft tunnel was first redrilled and then the component was clamped with the shaft tunnel as reference. Thus, everything was aligned relative to the shaft tunnel instead of the flange as originally planned. As a 
result, the shaft tunnel and gear chamber were slightly oblique to the CAD geometry. However, since the gear chamber and crescent were manufactured after the shaft tunnel, these critical geometries could be aligned precisely with each other. The final result is shown in Figure 13. At the top the raw bodies are shown after the manual support structure removal and the sandblasting process. In the middle, all relevant surfaces and threads are manufactured and the bearings are mounted. At the bottom, valves and gears are added.

\section{EXPERIMENTAL RESULTS}

\subsection{Test rig and experimental validation of the AM prototype pump}

For the evaluation of the performance of the AM internal gear pump a test rig for electro hydraulic drives at ifas was used. The hydraulic layout of the test rig is shown in Figure 14. One delivery port of the AM pump was used as the low pressure port and connected with the boost port

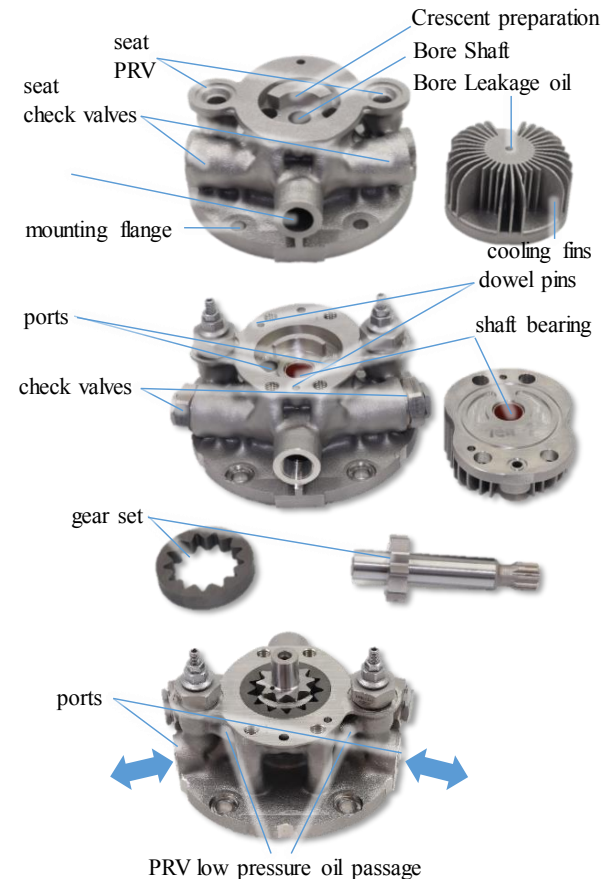

Figure 13: Power pack as-build (top), postprocessed (middle) and assembled (bottom)
" $\mathrm{B}$ " of the test rig. Therefore, a boost pump in combination with a mechanical PRV was used to pressurize the suction side. The other delivery port was connected with the load port "L". The flow rate sensor measured the delivered volume flow of the AM pump. An electric PRV was used to control the delivery pressure of the AM pump. The leakage port of the AM pump was connected with the reservoir port " $R$ ". The suction port " $S$ " of the test rig was not used. For the experiments, both PRVs inside the AM pump were adjusted to a pressure above the load pressure and therefore remained inactive. The test rig for electro hydraulic drives at the ifas lab is shown in Figure 15. The AM pump was mounted on the machine bed and connected to the ports according to Figure 14. The geometrical displacement of the AM pump was measured in the first step. For this purpose, the boost pressure was adjusted to be equal to the load pressure, resulting in a pressure difference between the low pressure port and the high pressure port close to 0 bar. The delivered volume flow was measured. The measured geometrical displacement was $2.57 \mathrm{~cm}^{3}$.

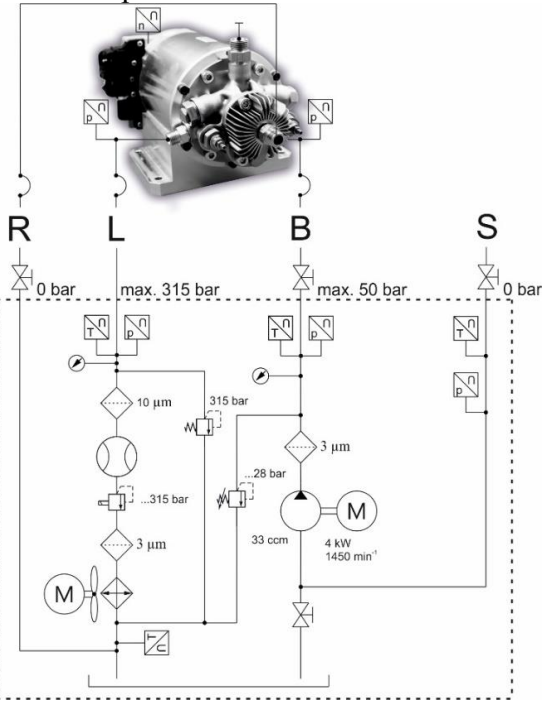

Figure 14: Hydraulic layout of the test rig for the AM pump

In the next step, the pump efficiency was measured. The rotational speed was set to a constant value and the load pressure was increased stepwise

When the maximum load pressure was reached, the load pressure was decreased and the rotational speed was set to a higher level. The temperature 
at the boost port was nearly constant at $40^{\circ} \mathrm{C}$ $+1{ }^{\circ} \mathrm{C} /-2^{\circ} \mathrm{C}$ for the presented measurements. HLP46 was used as the hydraulic fluid. Equation (1) - (3) is used for the efficiency calculation.

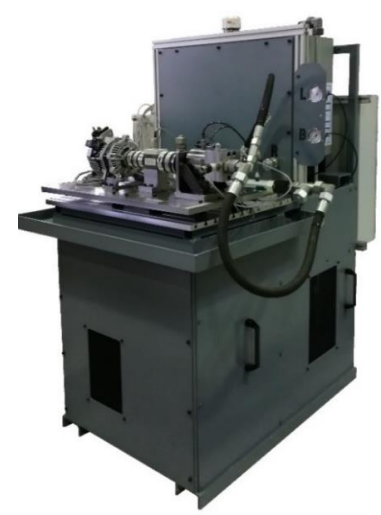

Figure 15: Test rig for experimental evaluation of the AM internal gear pump

$\eta_{v o l}^{P}=\frac{Q_{e f f}}{Q_{t h}}=\frac{Q_{e f f}}{n V_{g}}$

$\eta_{\text {hyd-mech }}^{P}=\frac{\eta_{\text {total }}^{P}}{\eta_{\text {vol }}^{P}}$

$\eta_{\text {total }}^{P}=\frac{P_{\text {hydr }}}{P_{\text {mech }}}$

The measured volumetric efficiency of the AM pump is shown in Figure 16. Due to higher leakage, the volumetric efficiency decreases at increasing delivery pressure. As expected, the volumetric efficiency increases with increasing rotational speed. Due to the hydraulic resonance frequency of the test rig some data points between 45 bar and 65 bar and low rotational speed are not shown in the presented efficiency maps. Due to a power limitation of the electrical motor, it was not always possible to achieve the maximum pressure at higher rotational speed. Figure 17 shows the hydromechanical efficiency of the AM pump. As expected, the hydromechanical efficiency increases with at higher load pressure. Due to increasing friction at higher rotational speed, the hydromechanical efficiency is lower at high rotational speed. Figure 18 shows the total efficiency of the AM pump. The maximum total efficiency is about $70 \%$. Due to the fact, that this is the first iteration in design and manufacturing process of an AM pump, the presented measurements proof the function of the AM pump. However, there is still potential for efficiency improvements.

\subsection{Summary}

AM is a comparatively new process that allows for greater freedom of design than conventional manufacturing processes. For fluid power technology, this opens up new possibilities in the flow-optimized design of components as well as for more compact and lighter components by eliminating interfaces and sealing surfaces. In this paper, the possibilities offered by AM and the necessary process chain were demonstrated using the example of the presented power pack. Compared to the conventional design, consisting of a series pump and a valve block connected with pipes, the installation space and weight could be reduced by a factor of four with the same nominal operating data. The powerpack was then tested on the test bench and its function verified. However, all functional surfaces were reworked in this design as their tribological properties are still unknown. This research gap must be closed in order to further reduce the necessary reworking and thus accelerate the immediate production of a component that is almost ready for use.

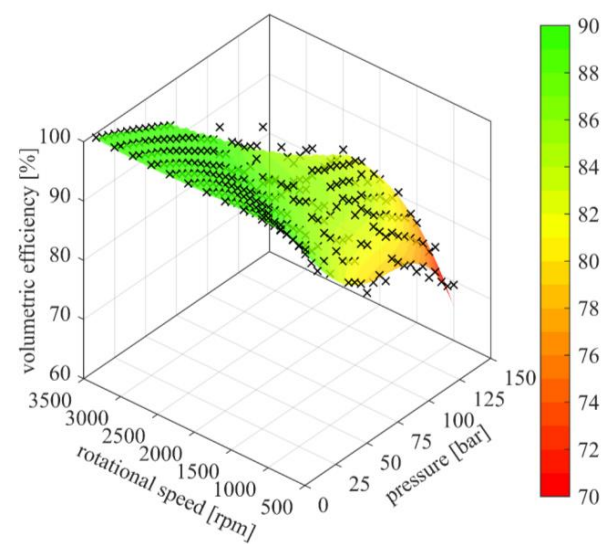

Figure 16: Volumetric efficiency 


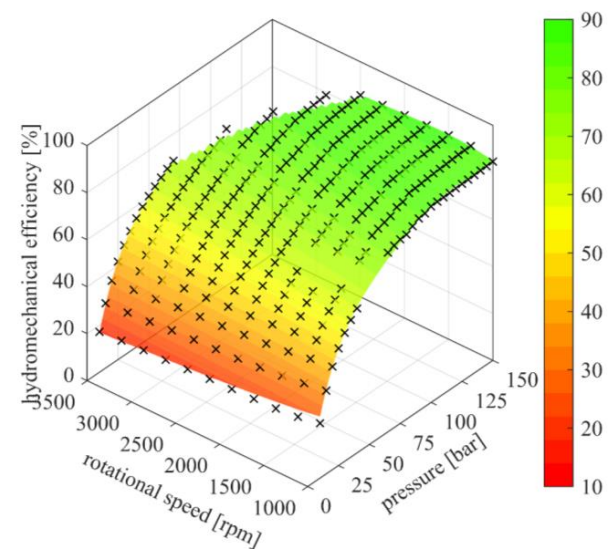

Figure 17: Hydromechanical efficiency

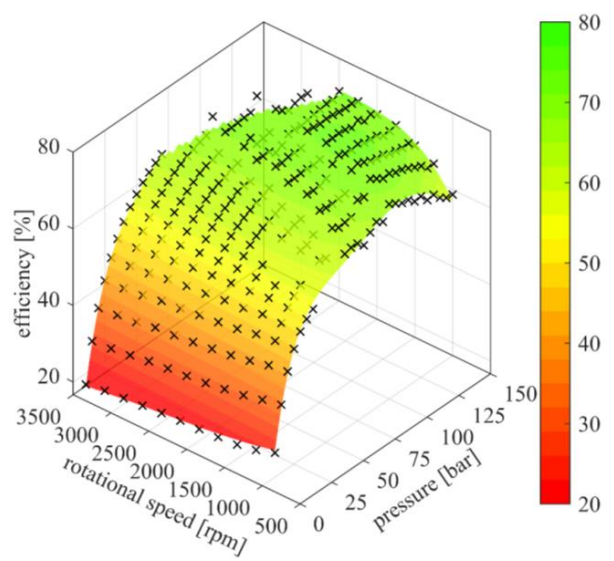

Figure 18: $\quad$ Overall efficiency

\section{ACKNOWLEDGEMENT}

The authors would like to thank Bucher Hydraulics $\mathrm{GmbH}$ for the extraordinarily extensive technical support in the implementation of this project and the open-mindedness towards this new technology and idea.

\section{REFERENCES}

[1] ISO / ASTM52900-15, Standard Terminology for Additive Manufacturing - General Principles - Terminology, ASTM International, West Conshohocken, PA, 2015.

[2] Burns, Marshall. "Automated fabrication: improving productivity in manufacturing", PTR Prentice Hall, Englewood Cliffs, New Jersey, 1993.

[3] Gebhardt, Andreas: "Generative Fertigungsverfahren. Additive Manufacturing und 3D
Drucken für Prototyping - Tooling Produktion", 4. Auflage. Carl Hanser Fachbuchverlag, München, 2013

[4] Wohlers Associates, "Wohlers Report 2017-3D Printing and Additive Manufacturing State of the Industry - Annual Worldwide Progress Repor", Fort Collins, Colorado, USA, 2017.

[5] Meiners, Wilhelm. "Direktes Selektives Laser Sintern einkomponentiger metallischer Werkstoffe" Dissertation, Aachen, Germany, Shaker Verlag, 1999.

[6] Buchbinder, Damien. „Generative Fertigung von Aluminiumbauteilen für die Serienproduktion AluGenerativ". Final project report, Aachen, 2010

[7] EOS GmbH. "Materials for Metal Additive Manufacturing", accessed October 16, 2018, https://www.eos.info/material-m.

[8] Concept Laser $\mathrm{GmbH}$, "Materials", accessed October 16, 2018, https://www.conceptlaser.de/en/products/materials.html.

[9] Matthiesen, Gunnar: "Additive Manufacturing Processes in Fluid Power - Properties and Opportunities Demonstrated at a FlowOptimized Fitting”, Proceedings of 2018 International Conference on Hydraulics and Pneumatics - HERVEX, 2018, Băile Govora, Romania

[10] Plummer, Andrew. "Additive Manufacture of Hydraulic Components" Paper presented at the The 9th International Conference on Fluid Power Transmission and Control, Zhejiang, China, April 11-13, 2017

[11] Cooper, David, Stanford, Mark, Kibble, Kevin a., Gibbons, Gregory j. "Additive Manufacturing for product improvement at Red Bull Technology", Material and Design 41, May 2012: 226-300.

[12] Semini, Claudio, Goldsmith Jake, Manfredi, Diego, Calignano, Flaviana, Ambrosio Elisa Paola, Pakkanen Jukka, Caldwell, Darwin G. "Additive manufacturing for agile legged robots with hydraulic actuation", Paper presented at 2015 International Conference on Advanced Robotics (ICAR), Istanbul, Turkey, July 27-31, 2015

[13] Guerrier, P., Zazynski, T., Gilson, E., Bowen. „Additive Manufacturing for Next Generation Actuation", Paper presented at 7th International Conference on Recent Advances in Aerospace Actuation Systems and Components, Toulouse, France, 16-18 March, 2016

[14] A. Breuer-Stercken, „Strukturanalyse als Werkzeug zur Geräuschminderung 
an hydraulischen Komponenten“, 10. Aachener Fluidtechnisches Kolloquium, 1992

[15] J. Ivantysyn, M. Ivantysynova, "Hydrostatic pumps and motors", Akademia Books International, New Delhi, India, ISBN-8185522-16-2, 2001

[16] W. Fiebig, K. Hell, "The New Way of Noise Reduction in External Gear Pumps", 7th International Fluid Power Conference, Aachen 2010

[17] T. Pietrzyk, et al. Design of a High Speed Internal Gear Pump to Increase the Power Density of Electro Hydraulic Actuators (EHA) in Mobile Applications, International Mechanical
Engineering Congress and Exposition, IMECE2019, November 11-14, 2019, Salt Lake City, UT, USA, 2019

[18] Hummel, Gerhard, Konrad, Tim, Harten, Oliver, Altmann, Alexander, Schubert, Frank, Kroll, Lothar. „Additive manufacturing for high pressure hydraulic valve manifold of Airbus A380 spoiler actuator", Paper presented at 7th International Conference on Recent Advances in Aerospace Actuation Systems and Components, Toulouse, France, 16-18 March, 2016

[19] VDI 3405 Part 3:2015-12; “Additive manufacturing processes, rapid manufacturing Design rules for part production using laser sintering and laser beam melting" 